\title{
Meteorological and ablation features of Potanin Glacier, Mongolian Altai Keiko KONYA' ${ }^{1}$, Tsutomu KADOTA ${ }^{1}$, Gombo DAVAA ${ }^{2}$, Hironori YABUKI ${ }^{1}$ and Tetsuo OHATA ${ }^{1}$
}

1 Research Institute for Global Change, Japan Agency for Marine-Earth Science and Technology, Yokosuka 237-0061, Japan 2 Institute of Meteorology and Hydrology, Ulaanbaatar, MONGOLIA

(Received August 11, 2009; Revised manuscript accepted May 6, 2010)

\begin{abstract}
An observational study was conducted for the first time at the ablation area of Potanin glacier, Tavan Bogd region, in western Mongolia in 2007-2008 in order to understand the meteorological and glaciological features. In the study, annual meteorological data and summer surface ablation data were obtained. It was found that the annual mean temperature was $-8.8^{\circ} \mathrm{C}$ on the glacier, and the surface albedo exhibited altitude dependence. Further, the precipitation measured near the glacier during summer was much larger than that measured at Ulgii. Surface energy balance was calculated by a gradient method; it revealed that shortwave radiation was the dominant heat source of surface ablation, whereas the contribution rate of turbulent heat flux was small. The ablation calculated by an equation constructed using the measured radiation showed fairly good correlations with the observed daily ablation, whereas the degree-day method showed good correlations for cumulative ablation. This study revealed the certain uniqueness of the glacio-climate in this region, and showed the further necessity of analysis on the relation of meteorological conditions and the mass balance of the glacier.
\end{abstract}

Key words: glacier, Altai, Mongolia, ablation, meteorology

\section{Introduction}

A change in the glacier mass in the world is an important index of global warming and influences the sea level. Therefore, the mass balance of glaciers must be studied not only in a limited area but also in as large regions of the world as possible so as to understand global changes. However, most of the glaciers that have been monitored for a long term are in Europe and North America (e.g., WGMS 2007), and extensive research has been insufficient in Asian regions, except in Himalayas and a part of China. A1though many glaciers exist in the Altai mountain range of central Asia, there have been only few observations of glacier mass balances e.g., at the Maliy Aktru and Leviy Aktru glaciers in the Russian Altai (e.g., WGMS 2007, 2008). Further, Fujita et al. (2004) found that large precipitation occurred on the Belukha glacier in summer and that this glacier is a summer-accumulation-type glacier. On the other hand, it has been recently reported that glaciers in Mongolia are shrinking (Kadota and Gombo, 2007), but no information on the mass balance has been obtained for the glaciers in the Mongolian Altai. In addition to a mass balance study, ice-core studies were conducted on the Belukha and Sofiyskiy glaciers (Fujita et al., 2004; Surazakov et al., 2007).

The objective of the present study was to know the meteorological and glaciological features related to the mass balance of the glaciers in Mongolian Altai. The main method of this study was in-situ observation on and around the glaciers. In addition, station data on a flatland was also used. The data obtained over the period of 2007 to 2008 were used.

\section{Study site}

There are glaciated mountain ranges in the Mongolia Altai in Western Mongolia. However, only a small number of glaciers are accessible and provide sufficient information. The Potanin glacier was selected as the study site because it is accessible by road, and it is the largest among the typical glaciers found in Mongolia. Over the past 100 years, Russian geographers visited this glacier several times, but they only made photographic observations. The Potanin glacier is situated in the Tavan Bogd region at the border of three countries: Mongolia, Russia, and China $\left(49^{\circ} 09^{\prime} \mathrm{N}, \quad 87^{\circ} 55^{\prime} \mathrm{E}\right)$. The Tavan Bogd region is located in a national park, where settlements are restricted; however, it is a popular place among tourists, 


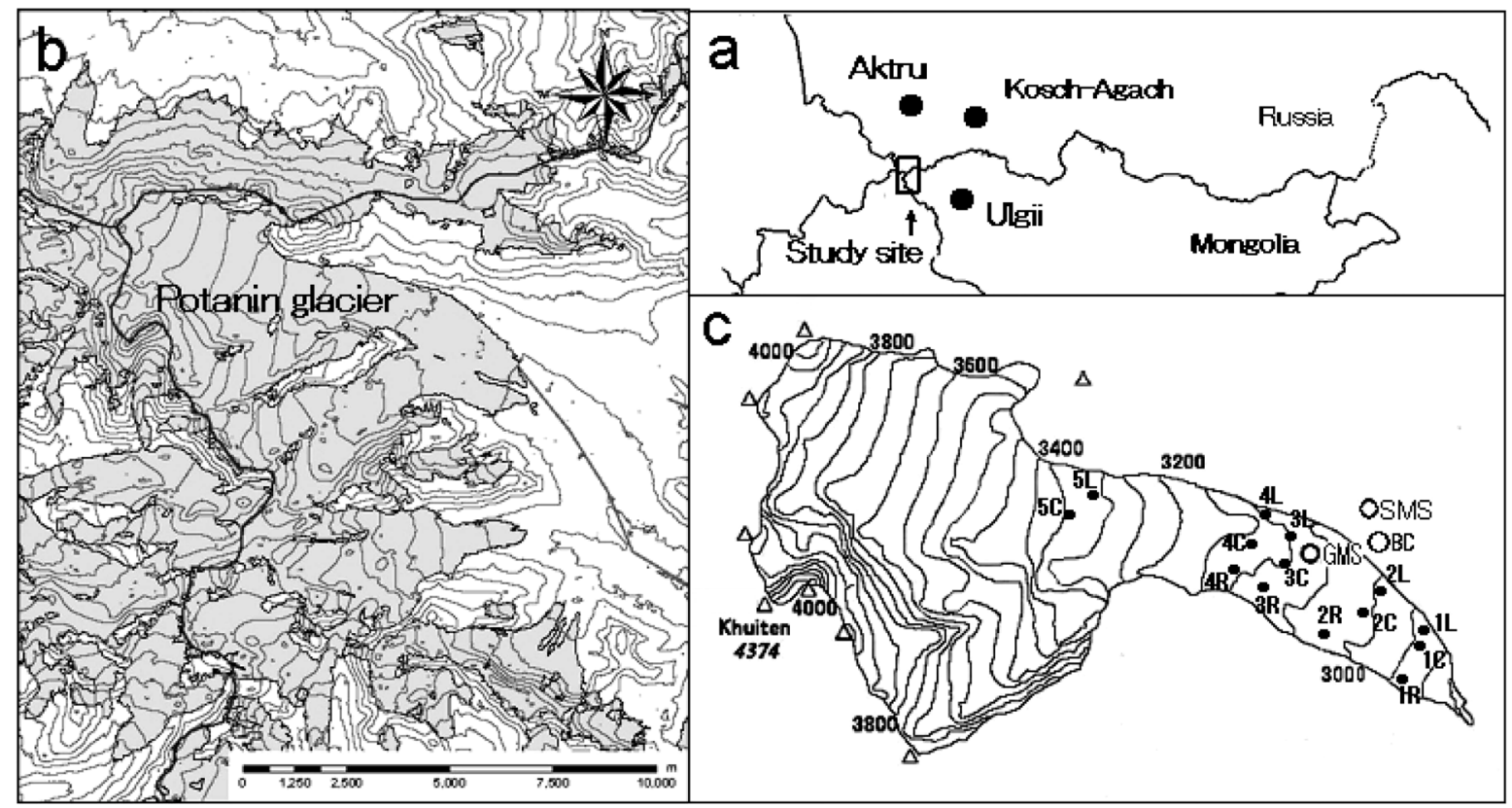

Fig. 1. Map of Potanin glacier. (a) Study sites in Mongolia and climate stations near the study sites, (b) studied glacier and topography in its vicinity, (c) meteorological stations (open circles) and stake locations (black circles) on the glacier. GMS and SMS denote meteorological stations located on the glacier and slope, respectively.

particularly among foreigners. The Potanin glacier flows down in the valley from Mt. Khuiten in the direction of east and turns around the equilibrium line altitude to south. It is $10.44 \mathrm{~km}$ long and ranges from 4365 to $2873 \mathrm{~m}$ a.s.l.; its area was estimated to be 24.34 $\mathrm{km}^{2}$ in 2001 (Yabuki, in preparation) (Fig. 1). A glacial lake was formed at the glacier terminus because of glacier retreat.

Many related hydrological and meteorological studies have been implemented in Mongolia (e.g., Davaa et al., 2006; Sugita et al., 2007; Miyazaki and Yasunari, 1999.). However, glaciated areas have not been paid much attention until now.

\section{Observations}

Meteorological observation was conducted on the ablation area of the glacier at $3040 \mathrm{~m}$ a.s.l. (GMS in Fig. 1) and on the side slope of the glacier at $3160 \mathrm{~m}$ a.s.l. (SMS in Fig. 1) from June 2007 to June 2008. Ablation and albedo measurements were made with a stake network. The stakes were set at every $50-100 \mathrm{~m}$ interval in elevation (Fig. 1c), beginning from $2900 \mathrm{~m}$ to $3300 \mathrm{~m}$ a.s.l. At each interval, they were set near the right bank, at the center, and near the left bank (Fig. 1c). The stake points are denoted as $2 \mathrm{~L}-5 \mathrm{C}$.

\subsection{Meteorological observation}

The side slope where the SMS was located was covered with grass during summer. The Automatic Weather Stations (AWS) are pictured at their two locations in Fig. 2, and the measurement devices are summarized in Table 1. All the instruments, except for the surface height sensor and the rain gauge, were (a)

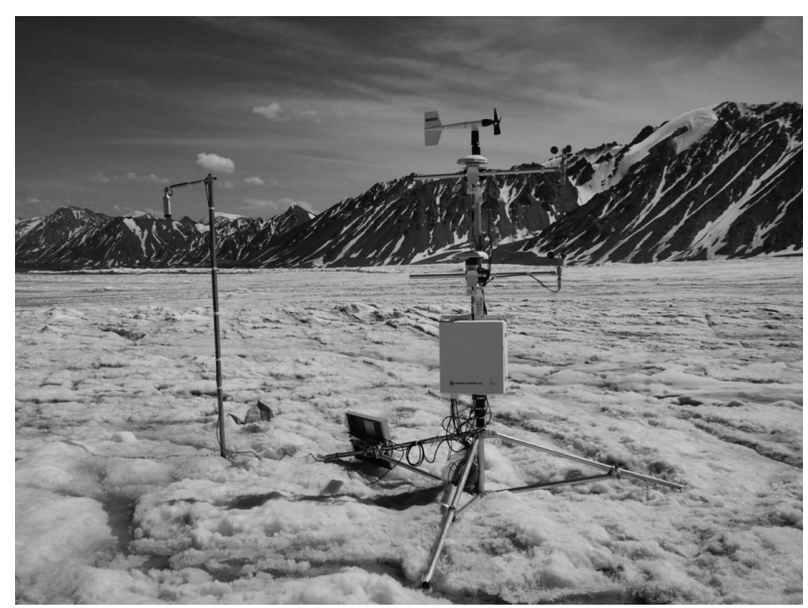

(b)

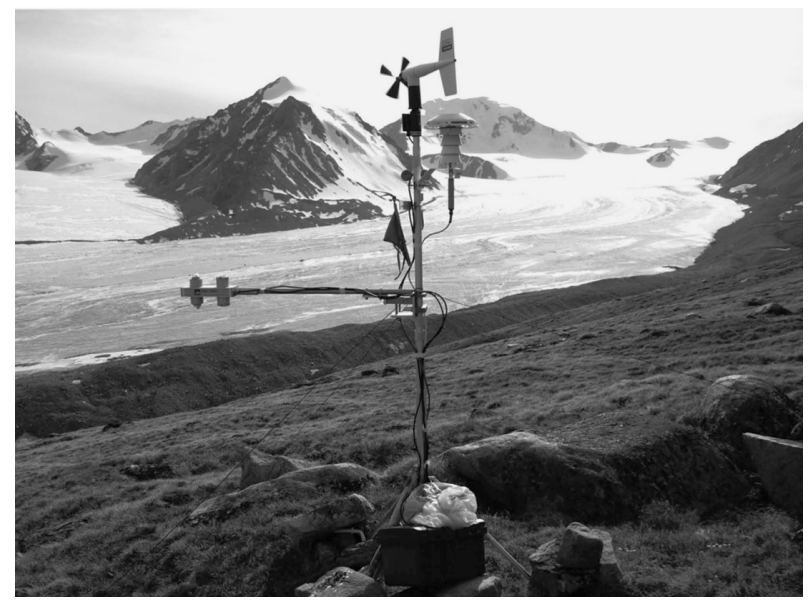

Fig. 2. (a) GMS and (b) SMS near the glacier shown in Fig. 1. 
Table 1. Instruments, setting heights, and measurement intervals of meteorological elements.

\begin{tabular}{|c|c|c|c|c|c|}
\hline Element & Sensor & Sensor type & $\begin{array}{l}\text { Height } \\
\text { (m) }\end{array}$ & Logger & interval \\
\hline \multicolumn{6}{|l|}{ Glacier } \\
\hline wind direction & Y5103 & potentiometer & 2.5 & CR10 & $10 \mathrm{~min}$ \\
\hline wind speed & AC750 & 3 cup & 1 and 2 & LS-3300ptV & $10 \mathrm{~min}$ or $1 \mathrm{~h}$ \\
\hline temperature & HMP-45D & Pt100 & 1 and 2 & LS-3300ptV & $10 \mathrm{~min}$ or $1 \mathrm{~h}$ \\
\hline humidity & HMP-45D & electrostatic capacity & 1 and 2 & LS-3300ptV & $10 \mathrm{~min}$ or $1 \mathrm{~h}$ \\
\hline radiation & MR-50 & thermoelectric pile & 1.5 & LS-3300ptV & $10 \mathrm{~min}$ or $1 \mathrm{~h}$ \\
\hline pressure & PTB100B & silicone capacitive & 1 & CR10 & $10 \mathrm{~min}$ \\
\hline snow depth & SR-50 & ultrasonic wave & & CR10 & $10 \mathrm{~min}$ \\
\hline \multicolumn{6}{|l|}{ Slope } \\
\hline wind direction & AC750 & potentiometer & 2 & KADEC & $10 \mathrm{~min}$ or $1 \mathrm{l}$ \\
\hline wind speed & 75 & 3 cup & 2 & LS-3300ptV & $10 \mathrm{~min}$ or $1 \mathrm{~h}$ \\
\hline temperature & HMP-45D & Pt100 & 2 & LS-3300ptV & $10 \min$ or $1 \mathrm{~h}$ \\
\hline humidity & HMP-45D & electrostatic capacity & 2 & LS-3300ptV & $10 \min$ or $1 \mathrm{~h}$ \\
\hline radiation & CNR1 & thermoelectric pile & 1 & LS-3300ptV & $10 \mathrm{~min}$ or $1 \mathrm{~h}$ \\
\hline precipitation & Y52203 & tripping-bucket & 2 & HIOKI & $30 \mathrm{~min}$ \\
\hline
\end{tabular}

set on a tripod during the summer season. The surface height sensor and rain gauge were set on the observation pole. Researchers and local observers were settled at the base camp (BC in Fig. 1), which was reachable within 30 min by walking from the GMS. The instruments were adjusted almost every day in order to adjust the verticality of the mast in summer. The observed meteorological elements were the air temperature, relative humidity, wind speed, wind direction, precipitation, atmospheric pressure, glacier surface height change, incoming shortwave radiation, reflected shortwave radiation, incoming longwave radiation, and outgoing longwave radiation. The measurement interval at the GMS was 10 min for all sensors for the summer season (from June 15 to September 10 ) and $1 \mathrm{~h}$ for the winter season (from September 11 to June 10 (Table 1)); at the SMS, it was 10 min in the summer season (from June 13 to September 6) and $1 \mathrm{~h}$ in the winter season (from September 11 to June 7). Precipitation was measured only at the SMS in the summer season because the device was not equipped with a heater.

\subsection{Ablation}

Continuous and periodic measurements of ablation were performed at the GMS and the stake network, respectively. At the GMS, the surface height change was measured with an ultrasonic distance sensor. In winter, the surface height data could not be acquired because of the sensor problem. Further, the stake measurement was made every day, except for some missing observation days (from June 25 to September 7). The surface at the GMS and all the stake sites was covered with ice during this entire period. The measured height change was converted to the water equivalent value by assuming the den- sity of ice as 0.9 .

\subsection{Surface albedo}

In addition to the albedo measurement at the GMS, albedo observations were conducted manually in June 2007 at stake sites. In order to determine the representativeness of the surface around the GMS, we made manual albedo observations around the GMS by using a portable shortwave radiation sensor on June $10,11,12$, and 15 . The measurements were conducted five times at each of the 9 to 10 points around the GMS on each day. The average of all observations was compared to the daily mean of the albedo data obtained at the GMS (Fig. 5).

Furthermore, in order to detect altitudinal variability, same measurements were also taken at three points near each of the stakes $2 \mathrm{~L}, 2 \mathrm{C}, 1 \mathrm{~L}, 1 \mathrm{C}, 1 \mathrm{R}, 3 \mathrm{~L}, 3$ $\mathrm{C}, 3 \mathrm{R}, 4 \mathrm{~L}$, and $4 \mathrm{C}$ by using the same instrument.

\section{Results and discussion}

\subsection{Observational results}

\subsubsection{Air temperature}

Figs. $3 \mathrm{a}$ and $3 \mathrm{~b}$ show the daily mean meteorological data obtained at the GMS and SMS, respectively, and Table. 2 lists the monthly mean values for the GMS. The annual mean temperature was $-8.8^{\circ} \mathrm{C}$ at the GMS and $-7.6^{\circ} \mathrm{C}$ at the SMS. The GMS on the glacier exhibited a lower temperature than that exhibited by the SMS, although its altitude was $120 \mathrm{~m}$ lower than that of the SMS. Further, the daily mean air temperature at the GMS fluctuated from $-29.6^{\circ} \mathrm{C}$ at minimum on January 18 to $7.6^{\circ} \mathrm{C}$ at maximum on July 21. The summer mean temperature at the GMS was $3.4^{\circ} \mathrm{C}$ (from June 15 to August 14) and that at the SMS was $4.8^{\circ} \mathrm{C}$ (from June 13 to August 14); this indicates that the difference in the summer temperatures is approximately the same as that in the annual temperatures. In addition, Miyazaki and Yasunari (1999) found "coreless winter" in Mongolia, which is typical in the polar regions, but it was not found in this region.

\subsubsection{Relative humidity}

The annual mean relative humidity at the GMS was $54.2 \%$ and that at the SMS was $53.4 \%$. The relative humidity in summer (JJA) was higher than that in other seasons in the year (Table 2). Further, the relative humidity and incoming longwave radiation were correlated at both of the GMS and SMS (Fig. 3). The correlation may be due to the cloudy conditions occurring from invasion of humid air mass. It was assumed that due to the evaporation from the glacier surface, the GMS will exhibit higher humidity than that expected from the SMS. However, the relative humidities at the SMS and GMS were comparable, and this suggests that the evaporation from the glacier surface was not sufficiently large to exert any effect 
on the water vapor at the sensor level (discussed in chapter 5).

\subsubsection{Wind speed}

The wind speed tended to be higher in winter than in summer (Table 2). The monthly wind speed ranged from 3 to $5 \mathrm{~m} \mathrm{~s}^{-1}$ in $2007 / 2008$. The maximum daily mean wind speed was $13.5 \mathrm{~m} \mathrm{~s}^{-1}$ on December 27 . It was a day of low temperature, high humidity, and low global radiation. The minimum daily mean wind speed was $1.2 \mathrm{~m} \mathrm{~s}^{-1}$ on December 6 at the SMS.

\subsubsection{Wind direction}

The wind direction was not obtained in winter due to the sensor problem. The prevailing wind direction at the GMS in summer was west to southwest. The prevailing wind direction in this area is the same as that in other areas in Mongolia (e.g., Sato et al., 2007). In addition to Westerlies, the wind direction should be affected by local topography because the GMS and SMS were located near the bottom of the valleys. However, such influence was only seen at the SMS in the form of Mountain-valley wind, but not at the GMS.

(a)
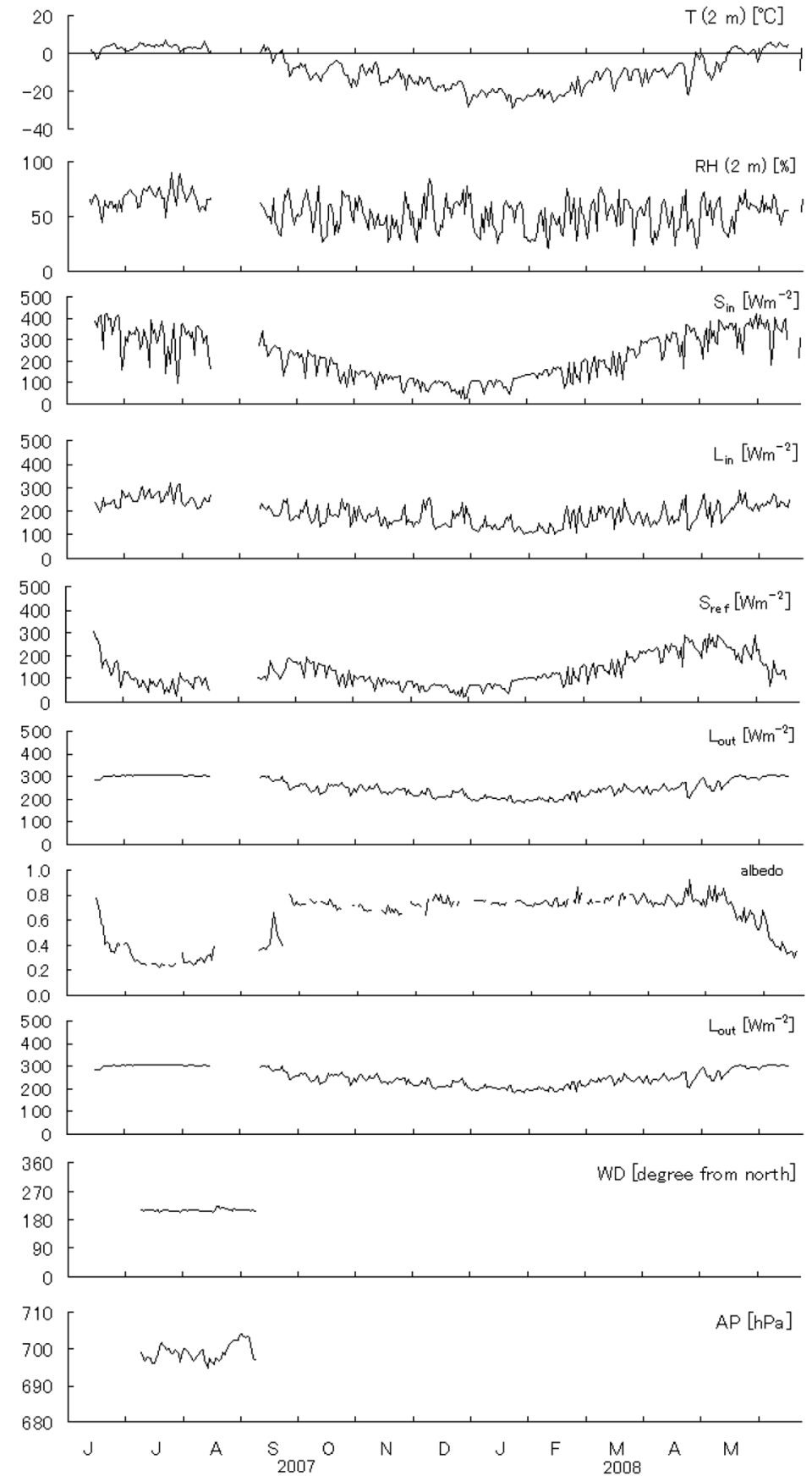

Fig. 3. Daily mean meteorological elements observed at (a) GMS and (b) SMS. T: air temperature, $R H$ : relative humidity, $S_{i n}$ : incoming shortwave radiation, $L_{i n}$ : incoming longwave radiation, $S_{\text {ref }}$. reflected shortwave radiation, $L_{\text {out }}$ outgoing longwave radiation, $w_{s}$ : wind speed, $w_{d}$ : wind direction, $A P$ : atmospheric pressure, and $P$ : precipitation as rain (including melted snow). 


\subsubsection{Radiation}

The high value of shortwave radiation of the days show an envelope curve, which implies that the an nual variation is regulated generally by potential clearsky solar radiation. During summer, the reflected shortwave radiation is higher at the GMS than that at the SMS because the albedo of the ice surface on the glacier is higher than that of the short grass on the slope. The surface conditions are favorable to outgoing longwave radiation. The outgoing longwave radiation was smaller in winter because of low surface temperature. The incoming longwave radiation was higher in summer than that in winter because the temperature and humidity are higher in summer (Fig. 3).

\subsubsection{Precipitation}

Precipitation, measured only in summer (from June 12 to September 8), revealed that there were 44 days $(49 \%$ of total) with rain in the period. The total precipitation during the period was $191.6 \mathrm{~mm}$. Large precipitation occurred on July 24, 28, and 29. The fact that these three days account for $37.4 \%$ of the

(b)
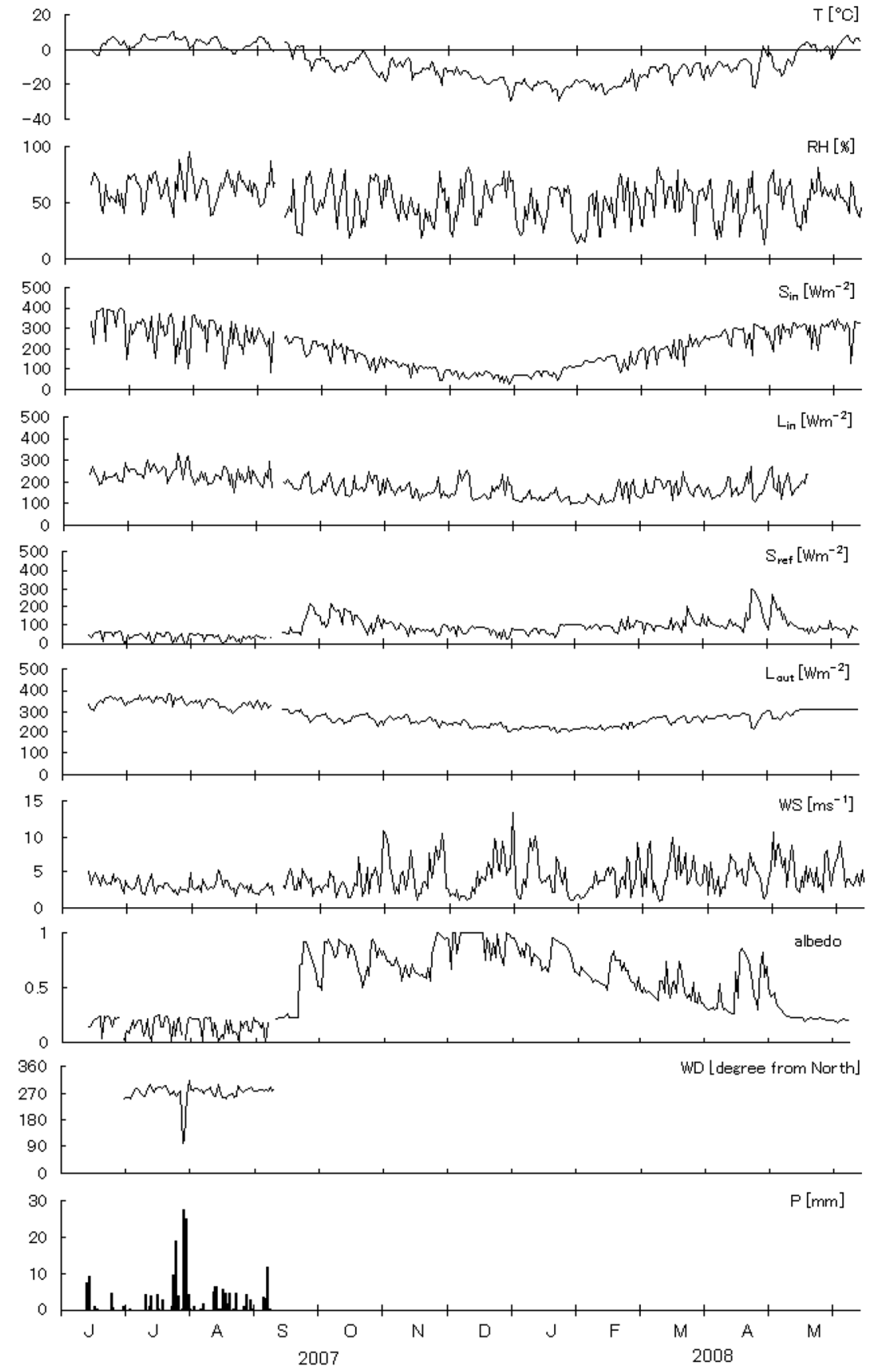

Fig. 3. continued. 
Table 2. Monthly, summer, and annual mean meteorological data at GMS. $\quad U$ : wind speed, $T$ : air temperature, $R H$ : relative humidity, and $S_{i n}$ : incoming shortwave radiation. Summer mean was calculated from the data collected from June 13 to August 14. Data were collected from June 15, 2007 to June 10, 2008. Data from August 15, 2007 to September 8, 2007 were missing. * denotes that some data for a month were missing, and the averages were calculated from rest of the data.

\begin{tabular}{|c|c|c|c|c|c|}
\hline & & $\mathrm{U}\left[\mathrm{ms}^{-1}\right]$ & $\mathrm{T}\left[{ }^{\circ} \mathrm{C}\right]$ & $\mathrm{RH}[\%]$ & $\operatorname{Sin}\left[\mathrm{Wm}^{-2}\right]$ \\
\hline \multirow[t]{7}{*}{07} & June & $3.6^{*}$ & $2.6^{*}$ & $60.7^{*}$ & $357.7^{*}$ \\
\hline & July & 3.2 & 3.9 & 71.7 & 295.5 \\
\hline & August & $3.1^{*}$ & $3.2^{*}$ & $65.0^{*}$ & $309.4^{*}$ \\
\hline & September & $3.2^{*}$ & $-3.1^{*}$ & $52.6^{*}$ & $236.6^{*}$ \\
\hline & October & 4.2 & -10.1 & 55.3 & 170.0 \\
\hline & November & 4.4 & -12.1 & 45.3 & 115.6 \\
\hline & December & 4.4 & -18.4 & 56.9 & 76.3 \\
\hline \multirow[t]{8}{*}{08} & January & 4.5 & -22.5 & 44.5 & 101.7 \\
\hline & February & 4.0 & -20.1 & 48.2 & 143.6 \\
\hline & March & 4.4 & -11.7 & 54.8 & 217.9 \\
\hline & April & 4.6 & -8.5 & 48.1 & 299.5 \\
\hline & May & 4.7 & -0.8 & 55.1 & 356.4 \\
\hline & June & $3.5^{*}$ & $4.7^{*}$ & $55.7^{*}$ & $333.9^{*}$ \\
\hline & Summer mean & 3.3 & 3.4 & 67.1 & 315.8 \\
\hline & Annual mean & 4.1 & -8.8 & 54.2 & 217.0 \\
\hline
\end{tabular}

period's total precipitation implies that the precipitation concentrated in certain days during summer. In addition, the precipitation amount was much higher than that at Ulgii $(54.2 \mathrm{~mm})$ situated in the flatland.

Most of the precipitation is said to occur in summer in all Mongolia according to the observations made in the flatland. However, other information on this area implies that precipitation occurs in other seasons also. The indication that the annual cycle in this region is different from that in other regions and is of higher precipitation than the flatland may be due to the orographic effect explained by Sato et al. (2006).

\subsubsection{Albedo}

Both of the GMS and SMS exhibit typical surface albedo for glacier and grass land surfaces, respectively. Only the result obtained at the GMS will be discussed. In winter, the surface albedo of the glacier has a high constant value and starts to decrease in April. During the decrease, temporal high albedo occurred probably due to snowfall. Further, the albedo had a minimum value of 0.22 in July and August. Thereafter, it increased to 0.81 on September 23 due to snowfall and then remained constantly as high as 0.7 after November. The manual observation of the albedo showed that the measurement made at the GMS can represent

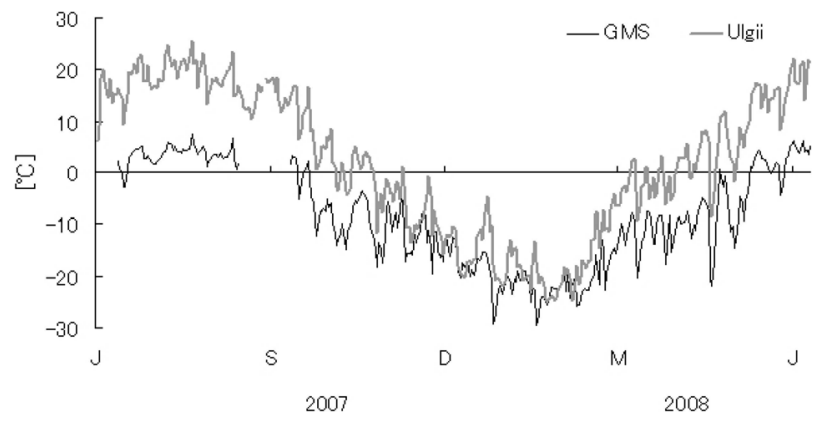

Fig. 4. Daily mean air temperature at GMS and Ulgii.

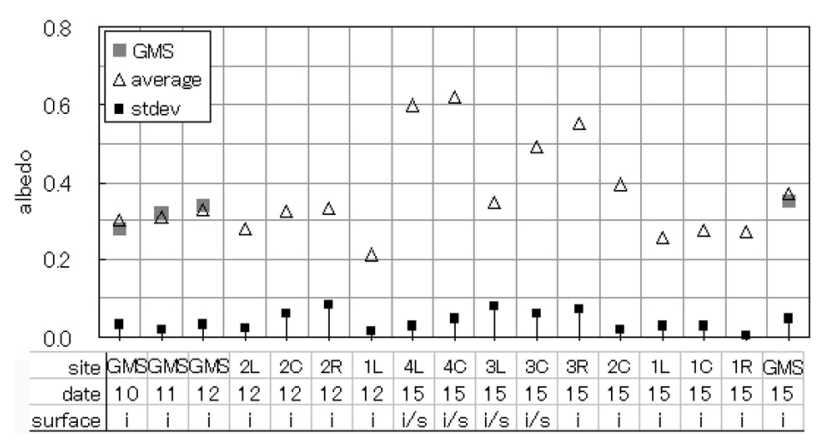

Fig. 5. Manually observed albedo variation. Legend: GMS: ultrasonic snow-depth sensor, average: averaged albedo measured by portable sensor for each site, and stdev: standard deviation for the measured rate. Table: site: measurement site, stake number is expressed as $1 \mathrm{R}$ for one stake located near the right bank at $2900 \mathrm{~m}$ a.s.1.; date: observation day in June 2007; and surface: surface condition as ice (i) or snow patches on ice (s/i).

the surface nearby the GMS. Albedo measured at various stakes exhibited altitudinal variability (Fig. 5): for the same day, it increased with the altitude. Albedo in lower altitude tends to be lower due to more surface dust on the surface (Ohata et al., 1980)

\subsection{Meteorology of region}

In order to compare the present observation data and the data obtained in the flatland and to clarify the condition of the observed year under the long observed period, the meteorological data gathered at a permanent station will be used. Long-term meteorological observations are made at a climate station in Ulgii $\left(48^{\circ} 933 \mathrm{~N}, 89^{\circ} 933 \mathrm{E}, 1715 \mathrm{~m}\right)$, and the results are shown in Fig. 4. Ulgii is a city with a population of about 97000 and is about $150 \mathrm{~km}$ east from the glacier; its location is shown in Fig. 1a. The annual temperature amplitude is larger at the glacier than in Ulgii. The summer temperature is higher in Ulgii than at the glacier because of the altitude difference, whereas the winter temperature is nearly the same (Fig. 4) as that at the glacier. In contrast, the temperature dropped in winter when radiative cooling occurred at both sites.

In order to know the climate change in this region, the annual mean air temperature was examined for Ulgii from 1961 to 2008 by using the daily mean 
data obtained by NCDC using monthly mean air temperature data (Fig. 6). The air temperature showed an increasing trend of $4.2^{\circ} \mathrm{C}$ in 100 years, and the years 2007 and 2008 were on the trend line. This implies that the observation year was not an abnormal year.

\subsection{Surface ablation}

The surface ablation was measured using stakes and an ultrasonic sensor at only the GMS (Fig. 7). The result from the ultrasonic sensor at the GMS and the nearby stakes $3 \mathrm{~L}$ and $3 \mathrm{C}$ indicated that the surface ablation occurred continuously in the summer in July and August and was almost constant (Fig. 7), which implies that the measurement was correct. The stake data also revealed that the ablation is small at a high altitude. This is because albedo is high at a higher

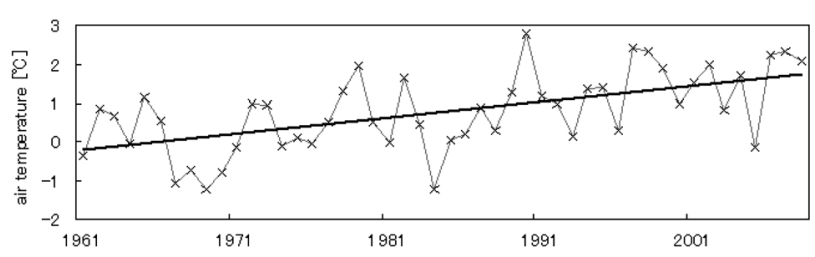

Fig. 6. Air temperature trend for last 50 years at Ulgii in Mongol Altai.

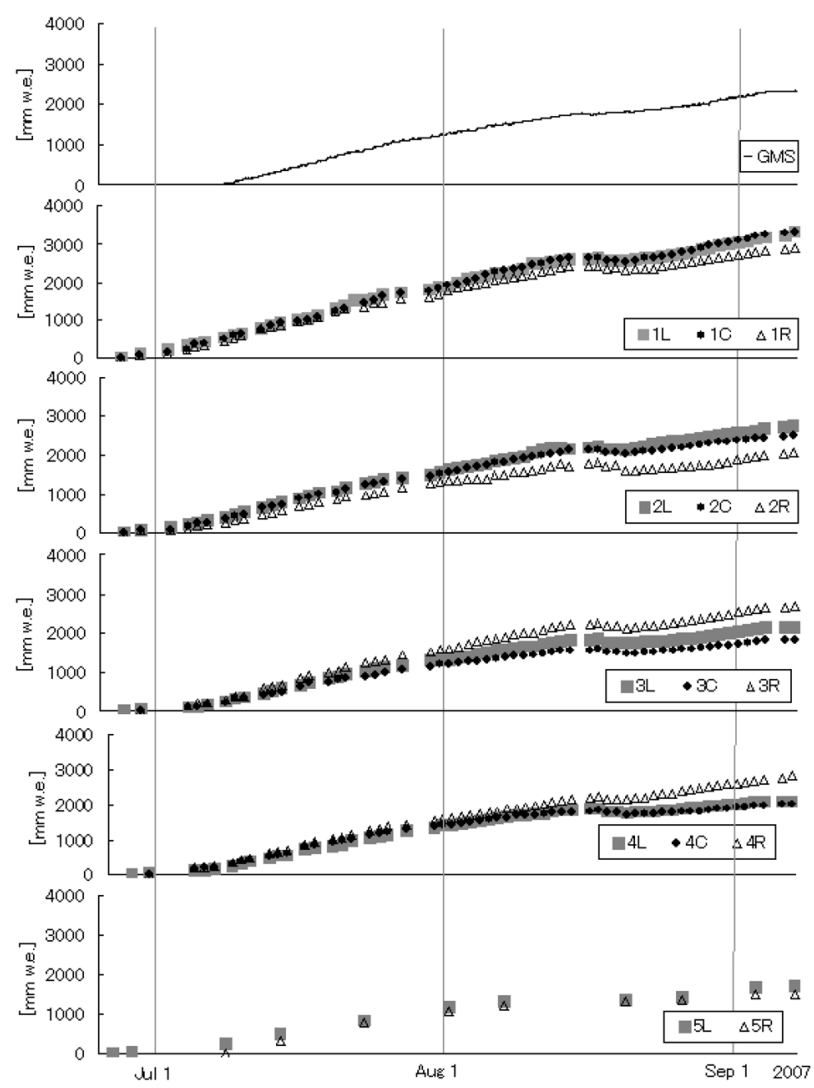

Fig.7. Surface ablation observed at AWS by ultrasonic snow-depth sensor and at stakes. $R, L$, and $C$ indicate the stake position on the right, left, and at the center of the transitional stake line, respectively. AWS and stake positions are shown in Fig. 1. altitude, as shown in Fig. 5. Thus, the net shortwave radiation would be smaller at higher places on the glacier. Also, temperature depends on the altitude, which is the reason of difference of ablation period. The highest value of the total ablation was observed at $1 \mathrm{C}$, namely, $3330 \mathrm{~mm}$ w.e., and the lowest ablation was at 5L, viz., $1716 \mathrm{~mm}$ w.e. from June 26 to Septem ber 7. The total ablation at the GMS was $2281 \mathrm{~mm}$ w.e. from July 8 to September 8.

\section{Energy balance on glacier surface}

The surface energy balance at the GMS was computed with the following equations in order to evaluate the heat source responsible for the ablation.

$$
Q=n e t S+n e t L+H+l E
$$

where $Q$ denotes the total energy for surface ablation; $n e t S$, the net shortwave radiation; netL, the net longwave radiation; $H$, the sensible heat flux; and $l E$, the latent heat flux. Further, the heat from rain is negligible. $H$ and $l E$ were calculated with the gradient method by using the following equations and the data measured at a height of $1 \mathrm{~m}$ and $2 \mathrm{~m}$ above the surface and.

$$
\begin{aligned}
& H=\left\{k /\left[\ln \left(z_{2} / z_{1}\right)\right]\right\}^{2} \rho c_{p}\left(U_{2}-U_{1}\right)\left(T_{1}-T_{2}\right)\left(P / P_{0}\right) \\
& l E=\left\{k /\left[\ln \left(z_{2} / z_{1}\right)\right]\right\}^{2} 0.622 \rho l\left(U_{2}-U_{1}\right)\left[\left(e_{1}-e_{2}\right) / P\right]
\end{aligned}
$$

where $k$ represents the Karman constant $(0.4) ; z$, the height from the surface; $U$, the wind speed; $T$, the air temperature; $\rho$, the air density; $P$, the atmospheric pressure; $c_{p}$, the specific heat of air at constant pressure; $e$, the water vapor pressure; and $l$, the latent heat flux for evaporation. The results of the daily energy balance calculations from June 27 to August 14 are shown in Fig. 8.

The calculated values will be compared with the observed values in two ways. First, the total observed ablation amount for $3 \mathrm{~L}$ from June 27 to August 14 was $1807 \mathrm{~mm}$ w.e., and the calculated amount was $1959 \mathrm{~mm}$ w.e. for the same period. Second, the total observed ablation amount for the GMS from July 8 to August 14 was $1740 \mathrm{~mm}$ w.e., and the calculated amount was $1599.5 \mathrm{~mm}$ w.e. From this, it can be said that the calculation was good in balance, and the residual includes the heat from rain, conductive heat, and errors in observations

The averaged total energy for ablation by calculation was $144.3 \mathrm{~W} \mathrm{~m}^{-2}$; the net shortwave radiation, $205.9 \mathrm{~W} \mathrm{~m}^{-2}$; the net longwave radiation, $-51.6 \mathrm{~W} \mathrm{~m}^{-2}$; the sensible heat flux, $8.1 \mathrm{~W} \mathrm{~m}^{-2}$; and the latent heat flux, $-18.1 \mathrm{~W} \mathrm{~m}^{-2}$. A high contribution rate of the net shortwave radiation to the surface ablation can be seen. Due to many clear days and a slight positive air temperature, the contribution rate of the net longwave radiation was negative. The latent heat flux 


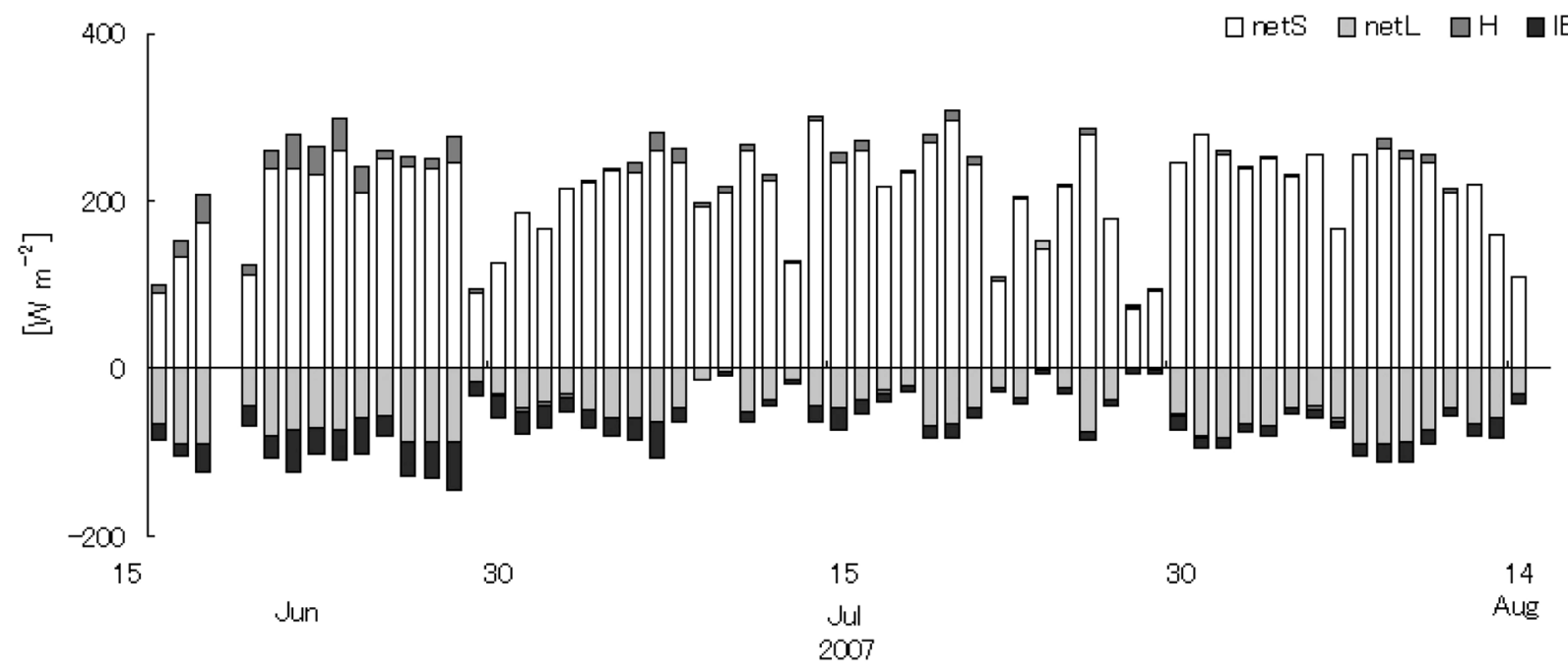

Fig. 8. Daily energy balance of Potanin glacier for summer 2007 calculated using meteorological data obtained at GMS (see Fig. 1). netS: net shortwave radiation, netL: net longwave radiation, $H$ : sensible heat flux, $l E$ : latent heat flux.

was also negative, which implies that sublimation (evaporation) occurred on the surface. However, because the relative humidity was about $70 \%$ (Table 2), the sublimation (evaporation) was not large, as compared to ablation, at the GMS.

\section{Expression of surface ablation with meteoro- logical data}

Surface ablation is an inevitable factor to estimate the mass balance of a glacier. However, its continuous measurement over a long period is extremely difficult to perform. Therefore, it must be estimated from meteorological data. This study used two methods to express the daily surface ablation rate of the Potanin glacier from meteorological data, which is easier than direct measurements of surface ablation.

\subsection{Expression with radiation term}

The first method was to construct an equation with the global radiation and albedo as parameters because the energy balance calculation revealed that the dominant heat source of the surface ablation was the net shortwave radiation. The following equation was derived by multi regression. The coefficients were determined so as to be best fitted to the measured amounts of the surface ablation, incoming shortwave radiation, and albedo.

$$
M=S_{\text {in }}(0.3-1.1 \times \alpha)+28.3 \quad(T>0, M>0)
$$

where $M$ indicates the surface ablation [mm w.e.]; $S_{i n}$, the incoming shortwave radiation $\left[\mathrm{W} \mathrm{m}^{-2}\right]$; and $\alpha$, the surface albedo. The average daily surface ablation was $46 \mathrm{~mm}$ w.e., and the standard deviation for the daily ablation was $13.1 \mathrm{~mm}$ w.e. The calculated and observed total surface ablation from July 8 to August 14 were $1744.2 \mathrm{~mm}$ w.e. and $1746.2 \mathrm{~mm}$ w.e., respec- tively, thus differing by a very small amount. In comparison, the correlation coefficient between the surface ablation and the incoming shortwave radiation was found to be 0.30 . This implies that the observed daily ablation is not correlated to the incoming shortwave radiation. On the other hand, the correlation coefficient calculated from the above expression that includes the incoming shortwave radiation and albedo was 0.68 , and it can be said that this expression is reliable.

\subsection{Degree-day method}

Secondly, we applied the degree-day method from the beginning to each day during July 9 to August 14 . It is the easiest and reliable method to estimate the daily cumulative surface ablation.

$$
\sum M=a \sum T \quad(T>0, M>0)
$$

where $M$ denotes surface ablation; $a$, the coefficient called the degree-day factor; $T$, the air temperature. Further, the sigma notation implies summation over the entire period.

In this study, the degree-day factor was as large as 12.06. As shown in the previous section, this glacier exhibits a very small contribution rate of temperature-related factors for surface ablation. In such cases, the degree-day factor is expected to be large. In addition, temperature will have a considerably large effect on the calculation by the degree-day method, and the daily values will be overestimated.

The daily mean temperature is not correlated to the daily surface ablation. Therefore, the correlation coefficient between the observed daily ablation and the daily ablation calculated by the degree-day method was 0.43 . On the other hand, the correlation coefficient between the observed cumulative ablation and the cumulative ablation calculated by the degreeday method was 1.00 because the degree-day factors 
were determined so as to be best-fitted. The degreeday method was insufficient for estimating the daily ablation but useful for calculating cumulative ablation.

\subsection{Comparison of methods}

Fig. 9 shows the cumulative ablation rate; this rate is determined on the basis of observation, by using eq. (4), and by using the degree-day method. The degree-day method shows good performance as well. However, the observed time series fluctuation was more consistent with the daily ablation rates calculated using eq. (4) than those determined using the degree-day method (Fig. 10). The calculation method employing eq. (4) could be useful for this glacier because the surface albedo at the GMS was relatively constant during the observation period. Fig. 10 shows that the ablation rate determined using the degree-day method was extremely high on July 21 and August 11. On these days, the temperature increased rapidly and the values calculated using the degree-day method were overestimated.

On the other hand, eq. (4) did not simulate the surface ablation well on July 24, July 30, and August 6. In the case of July 30 , this inaccuracy can be attributed to the fact that new snowfall occurred on July 29, as was determined from the albedo value. The density value used for calculating the ablation rate on this day was incorrect since ice density was considered. As a result, the "observed" value was overesti-

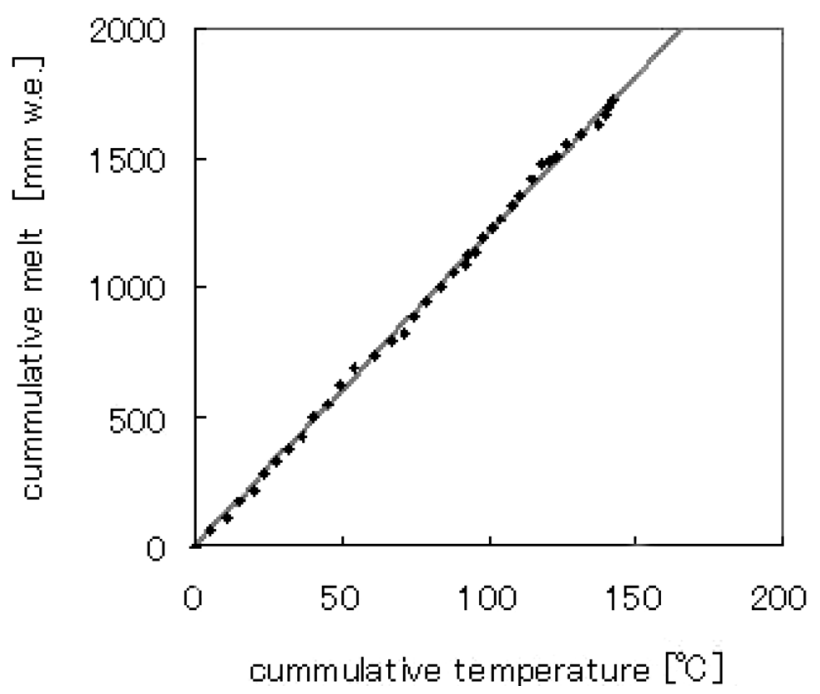

Fig. 9. Cumulative surface ablation vs. cumulative temperature. Solid line, black dots, and open triangles indicate the results obtained by the degree-day method; the observed data, and the results calculated by equation (4), respectively.

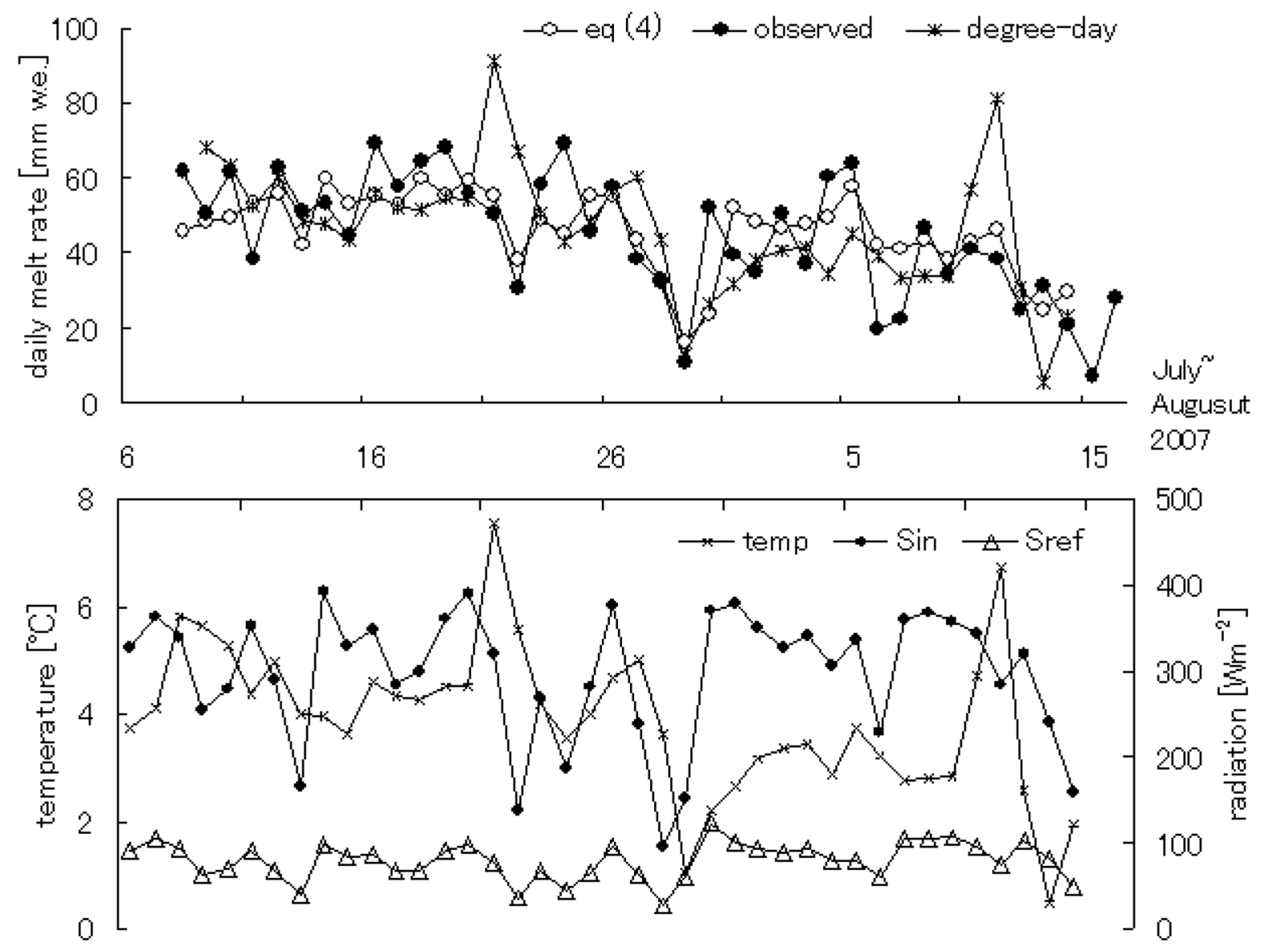

Fig. 10. Surface ablation estimated using meteorological data obtained from early July to mid August 2007. Open circles denote the ablation rate calculated by equation (4); black dots, observed ablation rate. For comparison, the ablation rates calculated by the degree-day method are also shown (asterisks). 
mated. In the cases of July 24 and August 6, we could not find the reason for this inaccuracy even after checking the energy balance. It may have been due to an error in the measured value of observed factors such as radiation or surface height measurement.

\section{Summary and conclusions}

An observational study was conducted for the first time at the ablation area of Potanin glacier, Tavan Bogd region, in western Mongolia in 2007-2008 in order to study the meteorological and glaciological features.

1. There was a typical mountain climate in the area of the Potanin glacier. The air temperature shows a different annual cycle, and precipitation possibly has different features as compared with the flatland.

2. The observation year was a normal year, as revealed by a trend of increasing temperature over the last few decades. The annual mean temperature was $-8.8^{\circ} \mathrm{C}$. The maximum and minimum daily air temperatures were 10.6 and $-30.3^{\circ} \mathrm{C}$ during the year, respectively. Precipitation occurred in $49 \%$ of the 89 days in summer and amounted to $192 \mathrm{~mm}$. The maximum daily wind speed ex ceeded $13.5 \mathrm{~m} \mathrm{~s}^{-1}$ in winter and was generally weaker in summer. Shortwave radiation was high during the year. The surface ablation amounted to $2.5 \mathrm{~m}$ w.e. at the GMS during 63 days in July and August. The albedo exhibited altitudinal variability.

3. The dominant heat source for the surface ablation was shortwave radiation, and the contribution rate of turbulent heat flux was small. The daily ablation can be calculated by the degree-day method and the radiation method with the measured net shortwave radiation during the observation period. The cumulative ablation for some days can be expressed by the degree-day method with the total ablation. However, the daily fluctuation was better reproduced by the radiation method than by the degree-day method.

Further study is required to investigate the following aspects. Winter precipitation and precipitation mechanism should be analyzed in order to detect when and in what quantity snow is supplied to this glacier. Because this study was conducted for only a year, continuous observations need to be made over an extended time period that does not include an anomalous year. Moreover, study should be under- taken in an accumulation area so as to estimate the mass balance of the glacier. This study revealed the certain uniqueness of the glacio-climate in this region, and showed the further necessity of analysis on the relation of meteorological conditions and the mass balance of the glacier.

\section{Acknowledgments}

We wish to thank the staff of the Institute of Meteorology and Hydrology, Ulaanbaatar, and the Hydro-meteorological Center of Bayan-Ulgii for their logistical support. We also appreciate an anonymous reviewer for helpful comments.

\section{References}

Davaa, G., Oyunbaatar, D. and Sugita M. (2006): Surface Water of Mongolia. Environment handbook of Mongolia, editorial committee of environment handbook of Mongolia ed., 42-54, 2007.01

Fujita. K., Takeuchi, N., Aizen, V. and Nikitin, S. (2004): Glaciological observations on the plateau of Belukha Glacier in the Altai Mountains, Russia from 2001-2003. Bull. Glaciol. Res., 21, 57-64.

Kadota, T. and Gombo, D. (2007): Recent glacier variations in Mongolia. Annals of Glaciology, 46, 185-188.

Miyazaki, S. and Yasunari, T. (1999): Abrupt Seasonal Change of Surface Climate Observed in Northern Mongolia by an Automatic Weather Station. J. Meteor. Soc. Japan, 77, 2, 583-593.

Ohata, T., Ikegami, K. and Higuchi, K. (1980): Albedo of Glacier AX010 during the summer season in Shorong Himal, East Nepal. Seppyo, 41, Special Issue 48-54.

Sato, T., Kimura, F. and Kitoh, A. (2006): Projection of Global Warming onto Regional Precipitation over Mongolia Using a Regional Climate Model. J. Hydrol., 333, 144-154.

Sato, T., Tsujimura, M., Yamanaka, T., Iwasaki, H., Sugimoto, A., Sugita, M., Kimura, F., Davaa, G. and Oyunbaatar, D. (2007): Water Sources in Semiarid Northeast Asia as Revealed by Field Observations and Isotope Transport Model. J. Geophys. Res., 112, D17112, doi: 10.1029/2006LD 008321.

Sugita, M., Azzaya, D., Adyasuren, T. and Brutsaert, W. (ed) (2007): The Rangelands Atmosphere-hydrosphere-biosphere Interaction Study Experiment in Northeastern Asia (RAISE). J. Hydrol., 333, 1, 1-164.

Surazakov, A., B., Aizen, V., B., Aizen, E., M. and Nikitin, S., A. (2007): Glacier Changes in the Sibelian Altai Mountains, Ob River Basin, (1952-2006) Estimated with High Resolution Imagery. Environ. Res. Lett., 2, 045017.

WGMS (2007) Glacier Mass Balance Bulletin, No.9. (2004-2005), ed. Haeberli, W., Zemp M., Kaab A., Paul, F. and Hoelzle M. ICSU (FAGS) IUGG (IACS)/UNEP/UNESCO/WMO, World Glacier Monitoring Service, Zurich, pp. 100.

WGMS (2008) Fluctuation of glaciers 2000-2005. (Vol. IX), ed Haeberli, W., Zemp, M., Kaab, A., Paul F. and Hoelzle. M. ICSU (FAGS) IUGG (IACS)/UNEP/UNESCO/WMO, World Glacier Monitoring Service, Zurich, pp. 266. 